\title{
Pengaruh Pengelolaan Diri Siswa Dan Karakter Guru terhadap Prestasi Belajar Siswa Kelas X SMK Satya Widya Surabaya dan SMK Tri Tunggal Surabaya
}

\author{
Abdul Malik, Suryaman, Retno Danu Rusmawati \\ Teknologi Pendidikan, Pascasarjana, Universitas PGRI Adi Buana Surabaya
}

\section{Edcomtech}

\section{Jurnal Kajian \\ Teknologi Pendidikan}

Volume 4, No 2, Oktober 2019

143-152

Submitted 18-07-2019

Accepted 28-08-2019

Corresponding Author

Abdul Malik

malikabdul6169@gmail.com

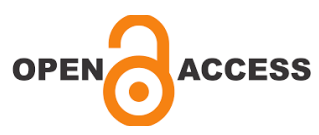

\begin{abstract}
Pendidikan pada dasarnya adalah usaha sadar untuk menumbuh-kembangkan potensi sumber daya siswa dengan memfasilitasi kegiatan belajar mereka. Suatu bangsa dikatakan maju bilamana kualitas sumber daya manusianya bagus, sedangkan kualitas sumber daya manusia itu sendiri tergantung pada kualitas pendidikannya. Mengingat begitu pentingnya peran pendidikan bagi kehidupan masyarakat, maka pemerintah berupaya meningkatkan mutu kualitas pendidikan, termasuk peningkatan mutu kemampuan siswa.Tujuan penelitian ini adalah untuk mengetahui pengaruh Self Regulated Learning ( pengelolaan diri siswa) dan karakter guru terhadap prestasi belajar siswa. Jenis penelitian yang digunakan dalam penelitian ini adalah korelasional dengan pendekatan kuantitatif, dimana penelitian ini bermaksud untuk mengetahui hubungan suatu variabel dengan variabel-variabel lain. Pengumpulan data diperoleh dengan melakukan tes(pretest,postest) angket dan dokumen . Analisis data menggunakan uji Anova Dua Jalur . Hasil penelitian menujukkan bahwa : (1) Ada pengaruh Self Regulated Learning terhadap prestasi belajar siswa, (2) Ada pengarahu Karakter Guru terhadap prestasi belajar siswa, (3) Terjadi interaksi antara Pengeloaan diri siswa dan Karakter Guru terhadap prestasi belajar siswa..
\end{abstract}

Kata Kunci: Pengelolaan Diri Siswa, Karakter guru, Prestasi belajar siswa

\begin{abstract}
Education is basically a conscious effort to develop the potential of students by facilitating their learning activities. A nation is said to be advanced when the quality of its human resources is good, while the quality of human resources itself depends on the quality of its education. Given the importance of the role of education in people's lives, the government seeks to improve the quality of education, including improving the quality of students' abilities.The purpose of this study was to determine the effect of Self Regulated Learning (student self-management) and teacher character on student learning achievement. The type of research used in this study is correlational with a quantitative approach, where this study intends to determine the relationship of a variable to other variables. Data collection is obtained by conducting tests, questionnaires and documents. Data analysis using the Two Way Anova test. The results of the study show that: (1) There is the effect of Self Regulated Learning on student learning achievement, (2) There is a guidance for Teacher Character on student achievement, (3) Interaction between Self Regulated Learning and Teacher Character on student achievement
\end{abstract}

Keywords: Self Regulated Learning, Teacher Character, Student Learning Achievement 


\section{PENDAHULUAN}

Suatu bangsa dikatakan maju bilamana kualitas sumber daya manusianya bagus, sedangkan kualitas sumber daya manusia itu sendiri tergantung pada kualitas pendidikannya. Pembangunan pendidikan merupakanbagian penting dari upaya menyeluruh dan sungguh-sungguh untuk meningkatkan harkat dan martabat bangsa (Sulthoni :2016) .Hal ini dudukung oleh pernyataan Yuliananingsih M.(2015): Pendidikan mempunyai peran penting dalam pembentukan generasi penerus bangsa sejak dini. Harkat dan martabat suatu bangsa sangat menentukan mutu pendidikannya. Siswa bisa bermutu apabila mereka mempunyai self regulated learning yang baik. Self regulated learning tinggi menunjukkan adanya peningkatan hasil belajar.( Yevina Maha Reni,dkk : 2017). Siswa yang self regulated learning tinggi memiliki nilai sebesar 19,53\% lebih tinggi dibandingkan self regulated learning rendah(Muhammad Djamil M. Nur:2017). Ditambahkan oleh Ibrahim (Nuke Lismarini,dkk : 2019) Hubungan signifikan antara SRL dan prestasi akademik ditemukan.

Dengan demikian betapa pentingnya Self Regulated Learning dalam proses pembelajaran. SRL mengacu pada proses keaktifan siswa dalam pembelajaran dan didefinisikan sebagai perencanaan yang disengaja dan pemantauan proses kognitif dan afektif yang terlibat dalam keberhasilan penyelesaian tugas-tugas akademik ,Palacios \& Gascon (Mohammad Djamil M. Nur:2017 ).Sebagaimana penelitian yang dilakukan oleh Octheria Friskilia S, Hendri Winata (2018): Peningkatan kualitas pendidikan dapat dilihat dari hasil belajar yang dicapai oleh para siswa. Kegiatan belajar mengajar dianggap berhasilapabila tujuan pembelajaran dapat tercapai dan diperoleh hasil belajar yang memuaskan.(Yustin Susanti,dkk: 2017). Proses belajar yang telah terjadi di sekolah akan menghasilkan suatu nilai akhir atau hasil pembelajaran yang bertujuan supaya kemampuan siswa terukur terhadap materi yang telah guru sampaikan. Dalam hal ini guru mempunyai peran yang penting dalam kelas.
Seperti diungkapkan oleh Nancy A.L,dkk (2017) agar proses pembelajaran berlangsung dengan baik (Lisnawati Rusmin1 Lisnawati Rusmin:2017) guru bertindak sebagai mentor dan fasilitator.. Hasil belajar siswa adalah hasil siswa yang merupakan salah satu gambaran keberhasilan kemampuan siswa, Novauli (Octheria Friskilia S, Hendri Winata: 2018). Penelitian ini bertujuan untuk : 1).Meruba pola pikir siswa agar supaya bisa mengontrol dirinya menjadi lebih baik dalam proses pembelajaran.2).Guru hendaknya sering memberi reward / penghargaan kepada siswa yang berprestasi dalam proses belajar mengajar

\section{METODE}

Jenis penelitian yang digunakan dalam penelitian ini adalahkorelasional dengan pendekatan kuantitatif, dimana penelitian ini bermaksud untuk mengetahui hubungan suatu variabel dengan variabel-variabel lain. Hubungan antara satu dengan beberapa variabel lain dinyatakan oleh besarnya koefisien korelasi dan signifikansi secara statistik. Korelasi positif berarti nilai yang tinggi dalam suatu variabel berhubungan dengan nilai yang tinggi pada variabel lainnya. Korelasi negatif berarti nilai yang tinggi dalam satu variabel berhubungan dengan nilai yang rendah dalam variabel lain. Sebagaimana dinyatakan oleh Wahidmurni (2017): penelitian kuantitatif adalah pendekatan untuk menguji teori obyektif dengan memeriksa hubungan antar variabel. Variabel-variabel ini, pada gilirannya, dapat diukur, biasanya pada instrumen, sehingga data bernomor dapat dianalisis menggunakan prosedur statistik.

Sebagaimana Sugiyono(Didik D.P, 2015) Metode penelitian yang digunakan adalah metode survei. Penggunaan metode survei akan memudahkan peneliti untuk memperoleh data. Dalam peneltian ini ada tiga variabel, yaitu: 1). Self Regulated Learning sebagai variabel bebas, 2). Karakter guru sebagai variabel moderator dan 3). Prestasi belajar sebagai variabel terikat. Dalam hal ini ada kelas kontrol dan kelas eksperimen. Adapun yang dimaksud dengan kelas kontrol 
yaitu kelas yang tidak dperlakukan alias tidak diujicobakan, sedangkan kelas eksperimen yaitu kelas yang diperlakukan dengan tujuan peneliti.

\section{Populasi dan sampel}

Jadi populasi adalah keseluruhan subjek penelitian yang berupa data kuantitatif mengukur dan menghitung. Dan populasi adalah keseluruhan subjek penelitian yang berupa data kuantitatif korelasional dan yang menjadi populasi dalam penelitian ini adalah siswa kelas X SMK Satya Widya Surabaya sebanyak dua kelas sebagai kelas eksperimen dan dua kelas X SMK Tri Tunggal Surabaya

Tabel 3.1.Distribusi Populasi Siswa

\begin{tabular}{|c|c|c|c|c|}
\hline Sekolah & Jurusan & Kelas & $\begin{array}{l}\text { Jumlah } \\
\text { Siswa }\end{array}$ & Jumlah \\
\hline \multirow{9}{*}{$\begin{array}{l}\text { SMK } \\
\text { Satya } \\
\text { Widya }\end{array}$} & UPW & $x$ & 25 & 231 \\
\hline & TB 1 & $X$ & 24 & \\
\hline & TB 2 & $x$ & 24 & \\
\hline & APh 1 & $X$ & 24 & \\
\hline & APh 2 & $x$ & 27 & \\
\hline & APh 3 & $x$ & 28 & \\
\hline & APh 4 & $x$ & 26 & \\
\hline & APh 5 & $x$ & 26 & \\
\hline & APh 6 & $X$ & 27 & \\
\hline \multirow{4}{*}{$\begin{array}{l}\text { SMK Tri } \\
\text { Tunggal }\end{array}$} & PM 1 & $x$ & 24 & 97 \\
\hline & PM 2 & $x$ & 25 & \\
\hline & APK 1 & $x$ & 24 & \\
\hline & APK 2 & $x$ & 24 & \\
\hline \multicolumn{4}{|c|}{ Jumlah total } & 328 \\
\hline
\end{tabular}

\section{Sampel dan Teknik Pengambilan}

Menurut Sugiyono (Stevany Atok : 2012) sampel adalah bagian dari jumlah dan karakteristik yang dimiliki oleh populasi tersebut.Sedangkan menurut Arikunto (Stevany Atok : 2012) Sampel adalah sebagian atau wakil populasi yang diteliti. Pengambilan sampel dilakukan terhadap tiga kelas yaitu satu kelas kontrol yaitu kelas X-AP 1 sebanyak 24 siswa dan dua kelas eksperimen yaitu kelas X- TB1 sebanyak 24 siswa dan TB2 sebanyak 24 siswa di SMK
Satya Widya. Sementara di SMK Tri Tunggal pengambilan sampel juga dilakukan terhadap tiga kelas yaitu kelas X-APK 1 sebanyak 24 siswa sebagai kelas kontrol, sedangkan kelas X-PM1sebanyak 24 siswa dan X-APK2 sebanyak 24 siswa sebagai kelas eksperimen. Kelas eksperimen adalahkelompok siswa yang mendapat perlakuan selama proses KBM berlangsung yang diajar oleh $\mathrm{g} u \mathrm{r} u$ berkarakter baik dan guru berkarakter buruk. Sedangkan kelas kontrol adalah kelompok siswa yang tidak mendapat perlakuan selama proses KBM berlangsung dengan kata lain seperti keadaan biasanya. Teknik pengambilan sample yang digunakan oleh penelitiadalah purposive sampling.purposive sampling adalah salah satu teknik sampling non random sampling dimana peneliti menentukan pengambilan sampeldengan cara menetapkan ciri-ciri khusus yang sesuai dengan tujuan penelitian sehingga diharapkan dapat menjawab permasalahan penelitian. Purposive sampling lebih tepat digunakan oleh para peneliti apabila memang sebuah penelitian memerlukan kriteria khusus agar sampel yang diambil nantinyasesuaidengan tujuan penelitian dapat memecahkan permasalahan penelitian serta dapat memberikan nilai yang lebih representatif. Sehingga teknik yang diambil dapat memenuhi tujuan peneltian yang sebenarnya

Tabel 3.2. Penentuan Subjek Penelitian

\begin{tabular}{|l|l|l|l|l|}
\hline Sekolah & Kelas & Kelas & $\begin{array}{l}\text { Jumlah } \\
\text { Siswa }\end{array}$ & Perlakuan \\
\hline \multirow{3}{*}{$\begin{array}{l}\text { SMK } \\
\text { Satya } \\
\text { Widya }\end{array}$} & Kontrol & X APh 1 & 24 & $\begin{array}{l}\text { Tidak } \\
\text { diper- } \\
\text { lakukan }\end{array}$ \\
\cline { 2 - 5 } & Eksperimen & X TB 2 & 24 & $\begin{array}{l}\text { Guru } \\
\text { ber- } \\
\text { karakter } \\
\text { baik }\end{array}$ \\
\cline { 2 - 5 } & Eksperimen & X TB 1 & 24 & $\begin{array}{l}\text { Guru } \\
\text { ber- } \\
\text { karakter } \\
\text { buruk }\end{array}$ \\
\hline
\end{tabular}




\begin{tabular}{|c|c|c|c|c|}
\hline \multirow{3}{*}{$\begin{array}{l}\text { SMK Tri } \\
\text { Tunggal }\end{array}$} & Kontrol & X APK1 & 24 & $\begin{array}{l}\text { Tidak } \\
\text { diper- } \\
\text { lakukan }\end{array}$ \\
\hline & Eksperimen & X PM 1 & 24 & $\begin{array}{l}\text { Guru } \\
\text { ber- } \\
\text { karakter } \\
\text { baik }\end{array}$ \\
\hline & Eksperimen & X APK 2 & 24 & $\begin{array}{l}\text { Guru } \\
\text { ber- } \\
\text { karakter } \\
\text { buruk }\end{array}$ \\
\hline \multicolumn{3}{|c|}{ Jumlah total } & 144 & \\
\hline
\end{tabular}

subjek penelitian dalam penelitian ini adalah 144 siswa dengan perincian 48 siswa dari SMK Satya Widya dan 48 siswa dari SMK Tri Tunggal

Tabel 3.3. Distribusi Subjek Penelitian

\begin{tabular}{|l|c|c|c|}
\hline Kelas & \multicolumn{2}{|c|}{ Jumlah Siswa } & Jumlah \\
\hline & $\begin{array}{c}\text { SMK } \\
\text { Satya } \\
\text { Widya }\end{array}$ & $\begin{array}{c}\text { SMK Tri } \\
\text { Tunggal }\end{array}$ & \\
\hline Kontrol & 24 & 24 & 48 \\
\hline Eksperimen & 48 & 48 & 96 \\
\hline Jumlah & 72 & 72 & 144 \\
\hline
\end{tabular}

\section{Instrumen Penelitian}

Instrumen penelitian sendiri adalah suatu alat yang digunakan untuk mengukur fenomena alam maupun sosial yang diamati,Sugiyono ( Stevany Atok: 2012 ). Ditambahkan oleh Suharsimi Arikunto (2012): Instrumen penelitian adalah alat bantu yang dipilih \& digunakan oleh peneliti dalam melakukan kegiatannya untuk mengumpulkan data agar kegiatan tersebut menjad sistematis \& dipermudah olehnya. Terdapat dua instrumen penelitian yang digunakan yaitu:1).Tes dan 2)Angket

\section{Teknik Pengumpulan Data}

Adapun teknik pengumpulan data yang digunakan oleh peneliti dalam penelitian ini adalah sebagai berikut : 1). Tes. Dalam penelitian ini peneliti menggunakan metode tes karena peneliti ingin mengukur kemapuan siswa terutama di bidang kognitif (pengetahuan inteligensi) dalam belajar bahasa Inggris siswa kelas X SMK Satya Widya dan SMK Tri Tunggal Surabaya. Seperti dinyatakan oleh Suharsimi Arikunto, (2012). Alat yang dapat digunakan dalam mengukur sesuatu hal dengan cara aturan yang sudah ditentukan disebut sebagai tes. Sementara itu peneliti di sini menggunakan metode tes prestasi untuk mendapatkan data tentang prestasi belajar, yang berupa nilai hasil dari tes yang diadakan oleh peneliti di kelas $X$ SMK Satya Widya Surabaya dan kelas $X$ SMK Tri Tunggal Surabaya. Dalam hal ini peneliti menggunakan anates versi 4.0.9 untuk mengetahui nilai hasil tes dari setiap murid. 2). Angket.Angket atau kuesioner merupakan teknik pengumpulan data yang dilakukan dengan 'cara memberi seperangkat pertanyaan atau pernyataan tertulis kepada responden untuk dijawab, Sugiyono(2015). Angket dalam penelitian ini terdiri dari daftar butir-butir pertanyaan yang dibagikan kepada responden dan dipergunakan untuk mengumpulkan data yang berkaitan dengan variabel self regulated learning siswa dan karakter guru. Untuk mengelola dan mengetahui hasil dari angket SRL siswa dan karakter guru, peneliti menggunakan skala likert. Karena skala likert adalah skala yang digunakan untuk mengukur persepsi, sikap atau pendapat seseorang atau kelompok mengenai sebuah peristiwa atafenomena sosial, berdasarkan definisi operasional yang telah ditetapka oleh peneliti.

\section{Teknik Analisis Data}

Adalah suatu metode atau cara untuk mengolah sebuah data menjadi informasi sehingga karakteristik data tersebut menjadi mudah untuk dipahami dan juga bermanfaat untuk menemukan solusi permasalahan, yang terutama adalah masalah tentang sebuah penelitian.

Dengan demikian teknik analisis data merupakan pengelolaan data, dari datadata yang sudah terkumpul. Sebelum melakukan uji prasyarat, hendaknya kita melakukan uji validitas pada suatu alat yang kita mau gunakan untuk memperoleh data penelitian. Uji validitas seharusnya disertai dangan uji realibilitas, karena kedua uji ini 
saling berkaitan satu sama lainnya. 1) Uji ValiditasMenurut Ahmad Dahlan (2015):valid berarti instrument tersebut dapat digunakan untuk mengukur apa yang seharusnya diukur. 2) Realibilitas. Realibilitas dalam bahasa Inggrinya realibility yang berarti hal yang dapat dipercaya (tahan uji).Sebuah tes dikatakan mempunyai reliabilitas yang tinggi jika tes terebut memberikan data hasil yang ajeg(tetap) walaupun diberikan pada waktu yang berbeda kepada responden yang sama. Hasil tes yang tetap atau seandainya berubah maka perubahan itu tidak signifikan maka tes tersebut dikatakan reliabel. 3) Uji Prasyarat Analisis.Sebelum peneliti menganilisis data, peneliti melakukan uji prasyarat. Adapun yang dimaksud uji prasyarat adalah sebagai berikut: a. Uji Normalitas Uji Normalitas adalah sebuah uji yang dilakukan dengan tujuan untuk menilai sebaran data pada sebuah kelompok data atau variabel, apakah sebaran data tersebut berdistribusi normal ataukah tidak. Di sini peneliti menggunakan uji normalitas versi Kolmogorov Smirnov, karena jumlah sampel besar yaitu lebih dari 50 siswa. Seperti yang diutarakan oleh Anwar Hidayat (2013) Gunakan uji Kolmogorov Smirnov untuk kepentingan uji normalitas apabila Jumlah Sample $N>50$. Sebaiknya gunakan pada $N>200$. Untuk $N$ kecil dibawah 50 sebaiknya gunakan uji Shapiro Wilk $b$. Uji Homogenitas Uji Homogenitas adalah pengujian yang digunakan untuk menguji apakah sebaran data dari dua varian atau lebih berasal dari populasi yang homogen keduanya, dapat dikatakan bahwa pada dasarnya uji homogenitas dimaksudkan untuk memperlihatkan bahwa dua atau lebih kelompok data sampel berasal dari populasi yang memiliki variansi yang sama.

Teknik analisis data yang digunakan oleh peneliti disini adalah sebagai berikut : a. dengan menggunakan uji anova two way direction ( uji anova dua arah ), karena yang diteliti oleh peneliti ada tiga variabel yaitu prestasi belajar siswa selanjutnya disebut variabel terikat ( $Y$ ) dan dua bebas yaitu Self Regulated Learning Siswaselanjutnya disebut Independent variabel (X1) dan Karakter guru selanjutnya disebut moderate variabel
(X2). Peneliti akan mengolah data dengan menggunakan SPSS versi 23.

\section{PEMBAHASAN}

Dalam penelitian ini data yang disajikan diperoleh dari angket, tes berupa pre-tes dan post-tes, serta dokumentasi prestasi belajar yang diambil dari nilai UAS siswa semester satu. Selanjutnya dalam penelitian ini ada tiga variabel yaitu variabel bebas, variabel moderator dan variabel terikat. Dalam penelitian ini self regulated learning ( pengelolaan diri siswa ) disebut variabel bebas yang dinotasikan dengan $\mathrm{X}_{1}$, karakter guru disebut variabel moderator yang dinotasikan dengan X2 dan prestasi belajar disebut variabel terikat yang dinotasikan dengan $\mathrm{Y}$. Untuk mengetahui data dari masing-masing variabel secara rinci dapat dilihat dalam uraian berikut ini :

\section{a. Self Regulated Learning (Pengelolaan Diri Siswa ) ( X 1 )}

Data hasil dari self regulated learning (pengeloaan diri siswa) diambil dari kedua sekolah kelas $X$ berupa angket yang telah diberikan kepada 96 responden berupa angket yang telah diberikan kepada 96 responden. Berdasarkan pengujian angket SRL di atas dengan bantuan SPSS versi 23 menujukkan pertanyaan tiap item memiliki nilai signifikansi $\geq 0,2199$, ini berarti $r$ hitung $>r$ tabel, sehingga $\mathrm{HO}$ ditolak dan disimpulkan bahwa tiap item pertanyaan pada angket tersebut adalah valid.

Adapun dari tiap item pertanyaan pada angket $S R L$ di atas setelah di uji realibiltas dengan menggunakan SPSS versi 23 memperoleh hasil 0,714 , ini berarti $r$ hitung $>r$ tabel yang menujukkan nilai signifikansi $\geq$ 0,2199, hal ini menyatakan bahwa tiap item pertanyaan pada angket $S R L$ reliabel seperti ditunjukkan pada tabel di bawah ini :

Tabel 4.1. Realibilitas angket SRL

\begin{tabular}{l|l}
\hline Crobanch's Alpha & Nof item \\
\hline, 714 & 26 \\
\hline
\end{tabular}


Satya Widya dan Tri Tunggal diperoleh nilai rata-rata SRL sebesar 71 . Nilai rata-rata ini menjadi dasar pengelompokan siswa dalam dua ategori yaitu siswa yang memiliki Self Regulated Learning tinggi dan siswa yang memiliki Self Regulated Learning rendah. Siswa dikategorikan mempunyai Self Regulated Learning tinggi apabila nilai $S R L \geq 71$. Siswa dikategorikan mempunyai Self Regulated Learning rendah apabila nilai perolehan SRL $<71$. Deskripsi Self Regulated Learning siswa dapat dilihat pada tabel di bawah ini.

Tabel 4.2. Deskripsi SRL

\begin{tabular}{|c|c|c|c|c|c|c|}
\hline & $z$ & 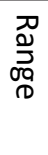 & $\begin{array}{l}3 . \\
\frac{3}{3} \\
\frac{2}{3}\end{array}$ & 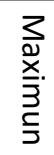 & $\begin{array}{l}3 \\
\stackrel{\mathbb{D}}{\stackrel{2}{J}}\end{array}$ & 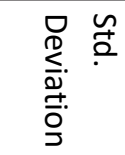 \\
\hline $\begin{array}{l}\text { 검 } \\
\text { ด } \\
\underline{\varrho}\end{array}$ & 46 & 23 & 71 & 94 & 76,33 & 4,962 \\
\hline 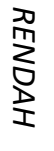 & 50 & 20 & 50 & 70 & 65,20 & 4,513 \\
\hline
\end{tabular}

Berdasarkan tabel 4.2, dari 96 siswa yang menjadi subjek penelitian yang memiliki SRL tinggi berjumlah 46 siswa dengan nilai rata-rata sebesar 76,33 dan standar deviasi sebesar 4,962. Sedangkan siswa yang memiliki Self Regulated Learning rendah berjumlah 50 siswa dengan nilai rata-rata sebesar 65,20 dan standar deviasi sebesar 4,513.

\section{b. Karakter Guru ( X2 )}

Data hasil dari karakter guru diambil dari kedua sekolah kelas X SMK Satya Widya dan Tri Tunggal berupa angket yang telah diberikan kepada 96 responden. Berdasarkan pengujian angket karakter guru di atas dengan bantuan SPSS versi 23 menujukkan pertanyaan tiap item memiliki nilai signifikansi $\geq 0,2006$, ini berarti $r$ hitung $>r$ tabel, sehingga $\mathrm{HO}$ ditolak dan disimpulkan bahwa tiap item pertanyaan pada angket tersebut adalah valid. Adapun dari tiap item pertanyaan pada angket karakter guru di atas setelah di uji realibiltas dengan menggunakan SPSS versi 23 memperoleh hasil 0,737, ini berarti $r$ hitung $>r$ tabel yang menujukkan nilai signifikansi $\geq 0,2006$, hal ini menyatakan bahwa tiap item pertanyaan pada angket karakter guru reliabel. Seperti ditunjukkan pada tabel di bawah :

Tabel 4.3. Realibilitas angket karakter guru

\begin{tabular}{l|l}
\hline Crobanch's Alpha & Nof item \\
\hline, 737 & 26 \\
\hline
\end{tabular}

Dari 96 subjek penelitian dari kedua SMK Satya Widya dan Tri Tunggal diperoleh nilai rata-rata karakter guru sebesar 73 . Guru dikategorikan mempunyai karakter baik apabila nilai perolehan $\geq 73$. Guru dikategorikan mempunyai karakter buruk apabila nilai perolehan $<73$. Deskripsi karakter guru bisa dilihat pada tabel. di bawah ini :

Tabel 4.4. Deskripsi karakter guru

\begin{tabular}{|c|c|c|c|c|c|c|}
\hline & $z$ & 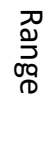 & $\begin{array}{l}3 \\
\frac{3}{3} \\
\frac{1}{3} \\
3\end{array}$ & $\begin{array}{l}3 \\
\frac{3}{2} \\
\frac{x}{3} \\
\frac{1}{3} \\
3\end{array}$ & $\begin{array}{l}3 \\
\stackrel{1}{\mathbb{D}} \\
\stackrel{1}{J}\end{array}$ & 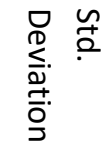 \\
\hline$\underset{\text { 罢 }}{ }$ & 52 & 16 & 73 & 89 & 78,04 & 4,343 \\
\hline $\begin{array}{l}\text { Фृ } \\
\text { 忍 } \\
\text { ᄃ }\end{array}$ & 44 & 24 & 48 & 72 & 66,09 & 5,025 \\
\hline 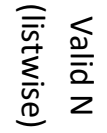 & 43 & & & & & \\
\hline
\end{tabular}

Berdasarkan tabel 4.4, dari penilaian 96 siswa yang menjadi subjek penelitian di SMK Satya Widya dan Tri Tunggal, guru yang berkarakter baik dinilai oleh 96 siswa dengan nilai rata-rata sebesar 78,04 dan standar deviasi sebesar 4,343 . Sedangkan guru yang memiliki karakter buruk dinilai oleh 44 siswa dengan nilai rata-rata sebesar 66,09 dan standar deviasi sebesar 5,025.

\section{c. Prestasi Belajar ( Y )}

Dari 96 subjek penelitian dari kedua SMK Satya Widya dan SMK Tri Tunggal diperoleh nilai rata-rata hasil belajar siswa setelah perlakuan sebesar 41. Hasil belajar siswa dikategorikan 
tinggi apabila nilai perolehan $\geq 41$. Hasil belajar siswa dikategorikan rendah apabila nilai perolehan < 41. Deskripsi hasil belajar setelah perlakuan bisa dilihat pada tabel dibawah ini.

Tabel 4.5. Deskripsi Prestasi Belajar Siswa Setelah Perlakuan

\begin{tabular}{|c|c|c|c|c|c|c|}
\hline & $\mathrm{N}$ & Range & Minimum & Maximum & Mean & Std. Deviation \\
\hline TINGGI & 33 & 40 & 50 & 90 & 63,03 & 14,467 \\
\hline RENDAH & 63 & 30 & 10 & 40 & 30,16 & 7,930 \\
\hline $\begin{array}{c}\text { Valid N } \\
\text { (listwise) }\end{array}$ & 33 & & & & & \\
\hline
\end{tabular}

Berdasarkan tabel 4.5, dari 96 siswa yang menjadi subjek penelitian di SMK Satya Widya dan Tri Tunggal, siswa yang mempunyai prestasi belajar tinggi sebesar 33 siswa dengan nilai rata-rata sebesar
63,03 dan standar deviasi sebesar 14,467. Sedangkan siswa yang mempunyai prestasi belajar rendah sebesar 63 dengan nilai rata-rata sebesar 30,16 dan standar deviasi sebesar 7,930.

Tabel 4.6. Uji Normalitas Data Self Regulated Learning, Karakter Guru Prestasi Belajar

\begin{tabular}{|l|l|l|l|l|}
\hline \multicolumn{2}{|l|}{} & PB & SRL & KARAKTER \\
\hline \multirow{2}{*}{ N } & 96 & 96 & 96 \\
\hline \multirow{2}{*}{ Normal Parameters ${ }^{\mathrm{a}, \mathrm{b}}$} & Mean & 70,53 & 60,77 & 69,79 \\
\cline { 2 - 5 } & Std. Deviation & 7,307 & 19,572 & 8,372 \\
\hline \multirow{2}{*}{$\begin{array}{l}\text { Most Extreme } \\
\text { Differences }\end{array}$} & Absolute &, 072 &, 172 &, 078 \\
\cline { 2 - 5 } & Positive &, 072 &, 109 &, 038 \\
\cline { 2 - 5 } & Negative &,- 070 &,- 172 &,- 078 \\
\hline \multirow{2}{*}{ Test Statistic } &, 072 &, 172 &, 078 \\
\hline \multirow{2}{*}{ Asymp. Sig. (2-tailed) } &, $200^{c, d}$ &, $000^{c}$ &, $176^{c}$ \\
\hline
\end{tabular}

Berdasarkan tabel 4.6. nilai signifikansi dari Self Regulated Learning, Karakter Guru Dan Prestasi belajar memperoleh nilai $\geq 0,05$, maka $\mathrm{HO}$ ditolak dan dapat disimpulkan bahwa variansi data antar kelompok SRL, Karakter Guru Dan Prestasi Belajar berdistribusi normal.

Tabel 4.7. pengujian homogenitas dengan Levene's test

\begin{tabular}{|l|l|l|l|}
\hline$F$ & df1 & df2 & Sig. \\
\hline 4,413 & 77 & 11 &, 005 \\
\hline
\end{tabular}

Berdasarkan tabel 4.7 nilai signifikansi (sig.) menunjukknan $\geq 0,05$ maka HO ditolak, ini berarti data variansi antara kelompok SRL,Karakter Guru dan Prestasi Belajar siswa adalah sama atau homogen.Teknik analisis data yang digunakan oleh peneliti disini adalah dengan menggunakan uji anova two way direction ( uji anova dua arah ), karena yang diteliti oleh peneliti ada tiga variabel. Peneliti akan mengolah data dengan menggunakan SPSS versi 23. 
Tabel 4.8. Data Hasil Pengujian Two Way Direction.

\begin{tabular}{|l|l|l|l|l|l|}
\hline Source & $\begin{array}{c}\text { Type III Sum of } \\
\text { Squares }\end{array}$ & \multicolumn{1}{|c|}{ df } & \multicolumn{1}{|c|}{$\begin{array}{c}\text { Mean } \\
\text { Square }\end{array}$} & F & Sig. \\
\hline Corrected Model & $4635,013^{\text {a }}$ & 77 & 60,195 & 4,827 &, 003 \\
\hline Intercept & 252450,746 & 1 & 252450,746 & 20245,139 &, 000 \\
\hline SRL & 1212,555 & 16 & 75,785 & 6,078 &, 002 \\
\hline KARAKTER & 2006,839 & 26 & 77,186 & 6,190 &, 002 \\
\hline SRL * KARAKTER & 1792,937 & 34 & 52,733 & 4,229 &, 007 \\
\hline Error & 137,167 & 11 & 12,470 & & \\
\hline Total & 447477,000 & 89 & & & \\
\hline Corrected Total & 4772,180 & 88 & & & \\
\hline
\end{tabular}

Harga $F_{\text {tabel }}$ pada taraf signifikansi $\alpha=5 \%$ $(0,05)$. Berdasarkan pada tabel 4.8 dapat dideskripsikan hasil pengujian hipotesis sebagai berikut:1). Ada pengaruh Self Regulated Learning terhadap prestasi belajar siswa Hasil uji hipotesis pertama diperoleh nilai $F=6,078$. Nilai tersebut dikonsultasikan dengan harga $F_{\text {tabel }}$ untuk taraf signifikansi $\alpha=5 \%$ dengan df 16 yaitu $F=0,4683$ dan nilai signifikansi (sig.) $=0,002$. Karena $F_{\text {hitung }}$ $(6,078)>F_{\text {tabel }}(0,4638)$ atau sig. $(0,002)$ $<0,05$ maka HO ditolak, sehingga dapat disimpulkan bahwa ada pengaruh Self Regulated Learning terhadap prestasi belajar siswa di kedua sekolah yaitu SMK Satya Widya dan Tri Tunggal.2). Ada pengaruh karakter guru terhadap prestasi belajar siswa. Hasil uji hipotesis kedua diperoleh nilai $F=6,190$. Nilai tersebut dikonsultasikan dengan harga $F_{\text {tabel }}$ untuk taraf signifikansi $\alpha=5 \%$ dengan df 26 yaitu $F=0,3739$ dan nilai signifikansi (sig.) $=0,002$. Karena $F_{\text {hitung }}(6,190)>F_{\text {tabel }}$ $(0,3739)$ atau sig. $(0,002)<0,05$ maka HO ditolak, sehingga dapat disimpulkan bahwa ada pengaruh karakter guru terhadap prestasi belajar siswa di kedua sekolah yaitu SMK Satya Widya dan Tri Tunggal. 3). Terjadi interaksi antara Self Regulated Learning dengan karakter guru terhadap prestasi belajar siswa. Hasil uji hipotesis ketiga diperoleh nilai $F=4,229$. Nilai tersebut dikonsultasikan dengan harga $F$ tabel untuk taraf signifikansi $\alpha=5 \%$ dengan df 34 yaitu $F=0,3291$ dan nilai signifikansi (sig.) $=0,007$. Karena $F_{\text {hitung }}$
$(4,229)>F_{\text {tabel }}(0,3291)$ atau sig. $(0,007)<0,05$ maka $\mathrm{HO}$ ditolak, sehingga dapat disimpulkan bahwa ada interaksi antara karakter guru dan Self Regulated Learning terhadap prestasi belajar sisiwa.

Berdasarkan dari hasil analisis data penelitian yang telah dilaksanakan, maka dapat diungkapkan pembahasan penelitian tentang pengaruh Self Regulated Learning (Pengelolaan Diri Siswa) dan Karakter Guru terhadap Prestasi Belajar Siswa sebagai berikut: maka dapat diungkapkan pembahasan penelitian tentang pengaruh Self Regulated Learning (Pengelolaan Diri Siswa) dan Karakter Guru terhadap Prestasi Belajar Siswa sebagai berikut: 1). Pengaruh Self Regulated Learning (X1) Terhadap Prestasi Belajar Siswa $(Y)$. Dari rumusan masalah yang telah diungkapkan pada bab sebelumnya bahwa dari uji hipotesis berdasarkan uji- t test dengan menggunkan spss versi 23, ditemukan bahwa ada pengaruh yang signifikan variabel Self Regulated Learning terhadap Prestasi Belajar Siswa baik di SMK Satya Widya maupun di SMK Tri Tunggal. Hal ini bisa kita lihat pada tabel 4.8 diatas yang menujukkan nilai signifikan Self Regulated Learning Siswa sebesar 0,002 <0,05. Ini berarti bahwa ada pengaruh yang signifikan variabel Self Regulated Learning Siswa terhadap Prestasi Belajar Siswa. Hal ini didukung oleh pendapat Bandura sebagaimana dikutip Lisya dan Subandi (Dewi Ikromatun Nisa:2016) regulasi diri merupakan kemampuan mengatur tingkah 
laku dan menjalankan tingkah laku tersebut sebagai strategi yang berpengaruh terhadap performansi seseorang mencapai tujuan atau prestasi sebagai bukti peningkatan. Senada yang dinyatakan oleh Marleen A. J. van Tetering et all ( 2018 ) Pengaturan diri yang lebih rendah bisa berdampak negatif terhadap prestasi belajar secara langsung . 2). Karakter Guru (X2) terhadap Prestasi Belajar ( Y ) Berdasarkan hasil data penelitian yang diolah dengan spss versi 23 menujukkan (Anggraeni: 2015 ) Banyak siswa yang tidak maksimal dalam belajar di sekolah karena memiliki hubungan yang negatif dengan guru mereka. Seperti dinyatakan Rega Afriana (2016) mengatakan dalam studi kuantitatifnya bahwa kompetensi kepribadian guru berpengaruh terhadap perkembangan belajar dan kepribadian siswa, hal ini menujukkan bahwa kepribadian atau karakter guru sangat erat dan signifikan kaitannya dengan motivasi prestasi siswa. 3). Interaksi antara Self Regulated Learnin g (X1) dan Karater Guru (X2) terhadap Prestasi Belajar Siswa (Y).

Dari hasil penelitian ini diperoleh bahwa ada interaksi antara Self Regulated Learning terhadap Prestasi Belajar Siswa. Sebagaimana penulis melakukan olah data dengan menggunakan SPSS [ versi 23 yang mana tertera di tabel 4.8 diatas hasil data menujukkan nilai signifikansi sebesar 0,007 di SMK Satya Widya dan Tri Tunggal, ini berarti nilai signifikansi dari kedua sekolah $<0,05$, hal ini menujukkan bahwasannya ada interaksi antara karakter guru dan Self Regulated Learning terhadap prestasi belajar siswa. Belajar Mandiri dan karakter guru sangat erat kaitannya. Oleh karena itu, pengaturan diri yang dievaluasi oleh guru dapat memberikan perkiraan yang tepat dari keterampilan pengaturan diri anak yang sangat penting untuk prestasi akademik, Deker al ( Marleen A. J.van Tetering et all : 2018 ).

\section{SIMPULAN}

Dari hasil penelitian yang dilakukan, maka peneliti mengambil kesimpulan berdasarkan temuan penelitian yang telah dianalisa. Adapun kesimpulannya adalah sebagai berikut : 1).Siswa yang empunyai $S R L$
(Pengelolaan Diri) yang tinggi mempunyai dampak positif dalam prestasi belajar dengan pengertian mencapai prestasi belajar yang memuaskan 2).Ada pengaruh karakter Guru terhadap prestasi belajar siswa. Semakin baik karakter guru semakin baik pula prestasi belajar siswa yang dicapai. 3).Terjadi interaksi antara Self Regulated Learning (Pengelolaan Diri Siswa ) dengan Karakter Guru terhadap Prestasi Belajar Siswa. Sehingga perlu para guru memperbaiki karakter yang buruk menjadi yang lebih baik agar supaya dalam proses mendidik dan membimbing siswa berdampak positif. Dengan demikian akan meningkat pula pengelolaan diri siswa yang nantinya berdampak pada prestasi belajar siswa itu sendiri.

\section{DAFTAR PUSTAKA}

Afriana,Rega.2016.,Pengaruh Kompetensi Kepribadian Guru Terhadap Minat Belajar Siswa.http://regaafriana. blogs.uny.ac.id/wp content/uploads/ sites/15504/2017/10/PengaruhKompetensi-Kepribadian-GuruTerhadap-Minat-Belajar-Siswa.pdf. Diakses tanggal 2/11/2018

Anggraeni, Puspita.2015. Hubungan Antara Persepsi Terhadap Tugas Akademik Dan Atraksi Interpersonal Siswa Terhadap Guru Dengan Regulasi Diri Siswa Program Olimpiade Sains Nasional (Osn) Sma Negeri 10 Samarinda.E-Journal Psikologi Fisip.http://ejournal.psikologi. fisipunmul.ac.id/site/wpcontent/ uploads/2015/05/ejournal\%20/0522-15-12-24-22).pdf. Diakses tanggal $2 / 10 / 2018$

Arikunto, Suharsimi, 2012, Prosedur Penelitian: Suatu Pendekatan Praktek, Jakarta: Rineka Cipta

Atok Stevany. 2012.Proposal Penelitian Pengaruh Motivasi Terhadap Prestasi Belajar Siswa Kelas Viii Smp Negeri Sekecamatan Bantul Tahun Ajaran 2011/2012.dari Https://Www. Academia.Edu/4647559/Proposal. Diakses tanggal 11/10/2018

Dahlan, Ahmad ,2015, Pengertian Uji Validitas dan Reliabilitas Secara Empirik 
https://www.eurekapendidikan. com/2015/10/pengertian-uji-validitasdan- reliabilitas-empirik-teoritik.html. Diakses tanggal 18/07/2019

Hidayat,Anwar,2013,Penjelasan Tentang Uji Normalitas dan Metode Perhitungan. https://www.statistikian. com/2013/01/uji-normalitas.html. Diakses tanggal 27/6/2019.

Lalawi,Nancy, Andriana, Kardi,Soeparman, P rastowo,Tjipto,2017, Pengembangan Perangkat Pembelajaran Berbasis $5 e$ Learning Cycle Pada Pokok Bahasan Energi Untuk Meningkatkan Hasil Belajar Siswa Sekolah Menengah Pertama. Jurnal Penelitian Pendidikan Vol. 34 Nomor 2 Tahun 2017.Diakses $15 / 7 / 2019$

Lismarini, Nuke, Mustaji, Walujo Djoko Adi.,2019,. The Effect of Realia Strategy and Self-Regulated Learning (SRL) to The English Learning Result Volume 4, No 1, 49-55.http://journal2.um.ac. id/index.php/edcomtech/article/ view/6875/3892. Diakses tanggal $17 / 07 / 2019$

M.Yuliananingsih,2015,PelaksanaanPendidikan Karakter Di Program Studi Pendidikan Pancasila Dan Kewarganegaraan Ikip Pgri Pontianak Jurnal Edukasi, Vol. 13, No. 2, Desember 2015 Diakses 7/8/2019.

Nisa, D.I. 2016.Regulasi Diri Dalam Belajar Antara Mahasiswa Fakultas Ushuluddin Angkatan 2015 Yang Tinggal Di Pesantren Dan Tidak Di Pesantren,Jurusan Tasawuf Dan Psikoterapi Fakultas Ushuluddin Dan Humaniora Universitas Islam Negeri Walisongo Semarang. http://eprints. walisongo.ac.id/7004/ Diakses tanggal 21/11/2018

Nur, Mohammad Djamil M, 2017, Pengaruh Strategi Pembelajaran Fisika Berbasis Website Terhadap Hasil Belajar Pada Siswa Yang Memiliki Selfregulated Learning (Srl) Yang BerbedA || Edcomtech Volume 2, Nomor 1, April 2017.Diakses $7 / 8 / 2019$
Prasetya, Didik Dwi, 2015, Kesiapan Pembelajaran Berbasis Buku Digital Jurnal Teknologi Elektro Dan Kejuruan. Volume 24 Nomor 2: September 2015 http://journal.um.ac.id/index.php/ tekno/article/view/5169/3895 Diakses 7/7/2019

Reni, Yevina Maha, Kuswandi Dedi, Sihkabuden, Pengaruh Strategi Pembelajaran Dan Self Regulated Learning Terhadap Hasil Belajar,|| Jinotep, Volume 4, Nomor 1, Oktober 2017. Diakses 7/8/2019

Rusmin, Lisnawati, Saptawati, Rosdiana, Hasani Sakka,2017, Improvement Of Learning Outcomes Of Freedom Of Organization For Elementary School Student Through Cooperative Learning Of Type Of Jigsaw International Journal of Education and Research Vol. 5 No. 9 September 2017. Diakses 14/7/2019

S., Octheria Friskilia,,Winata Hendri. 2018, Regulasi Diri (Pengaturan Diri) Sebagai Determinan Hasil Belajar Siswa Sekolah Menengah Kejuruan.Jurnal Pendidikan Manajemen Perkantoran1(2), 37-4. Diakses 13/6/2019

Sugiyono,2015,Metode Penelitian Kombinasi (Mix Methods). Bandung: Alfabeta

Sulthoni,2016, Pendidikan Nilai Berbasis Keluarga,Sekolah, Dan Masyarakat II Edcomtech Volume 1, Nomor 1, April 2016.Diakses 7/8/2019

Susanti, Yustin, Wahjoedi, Utaya,Sugeng Peningkatan Aktivitas Dan Hasil Belajar Melalui Pembelajaran Kooperatif Tipe Stad,Mei 2017. Jurnal Pendidikan, Vol. 2, No. 5, Bln Mei, Thn 2017, Hal 661666 http://journal.um.ac.id/index.php/ jptpp/article/view/9160/4422. Diakses $6 / 8 / 2019$

Van Tetering, A. J.M, de Groot, H.M.R, Jolles J. 2018,.Teacher-Evaluated Self-Regulation Is Related to School Achievement and Influenced by Parental Education in Schoolchildren Aged 8-12: https:// www.ncbi.nlm.nih.gov/pmc/articles/ PMC5893787/. Diakses 7/8/2019 